\title{
Collective impact: dialogue at the interface of the colliding systems of philanthropy
}

\section{Robert M. Yawson*}

School of Business,

Quinnipiac University,

275 Mt. Carmel Avenue,

Hamden, CT 06516, USA

Email: robert.yawson@qu.edu

*Corresponding author

\section{Gayle Peterson}

\author{
Said Business School, \\ University of Oxford, \\ Egrove Park, Oxford OX15NY, UK \\ Email: gayle.peterson@sbs.ox.ac.uk \\ and \\ pfc Social Impact Advisors, \\ St. Paul, MN, USA
}

\section{Ivy Johnson-Kanda}

College of Arts and Sciences,

Quinnipiac University,

275 Mt. Carmel Avenue,

Hamden, CT 06516, USA

Email: Ivy.Johnson-Kanda@qu.edu

\begin{abstract}
Collective impact as a collaborative effort arose from the acknowledgement that existing methods and development approaches were incapable of addressing large-scale and long-term societal problems, the so-called wicked problems. By creating a model of the ecosystem of organisations around a particular issue, a funder can understand who else is working in the same space, identify potential allies, and anticipate political or economic challenges that might arise. In a case study to assess the developmental impacts of foreign aid and developmental programs on women and children in one of the poorest districts in Ghana, we developed an approach through which collective impact can be initiated and evaluated. Through the life of Lamisi Seidu, a typical, poor, rural Ghanaian woman, we tell the symbolic story of poor women living in rural, peri-urban, and urban areas all over the world. We examine what defines collective impact, how such initiatives are structured, and the challenges in creating collective impact initiatives that achieve successes that are both long lasting and large scale. We also discuss the landscape mapping approach we developed.
\end{abstract}


Keywords: collaboration; collective impact; dialogue at the interface; landscape mapping; networking; storytelling; stakeholder analysis; wicked problems.

Reference to this paper should be made as follows: Yawson, R.M., Peterson, G. and Johnson-Kanda, I. (2020) 'Collective impact: dialogue at the interface of the colliding systems of philanthropy', World Review of Entrepreneurship, Management and Sustainable Development, Vol. 16, No. 1, pp.1-21.

Biographical notes: Robert $M$. Yawson is an Assistant Professor of Management at the School of Business, Quinnipiac University, USA. He has a BS in Chemistry and MPhil in Biochemistry, University of Ghana; Post Graduate Certificate in Food Management, Hebrew University of Jerusalem; MS in Science, Technology and Environmental Policy, Hubert H. Humphrey School of Public Affairs, University of Minnesota; and $\mathrm{PhD}$ in Organisational Leadership, Policy and Development, University of Minnesota. His current research is on using the 'wicked problem construct' of leadership for organisational development and change and also using a systems approach to human resource development for emerging technologies.

Gayle Peterson is founder of the Oxford Women Transforming Leadership Programme and direct the Oxford Impact Investing Programme and Oxford Social Finance, Saïd Business School, Oxford University. She has advanced degrees from HEC Paris School of Management, Oxford University, and the University of Chicago. As Managing Director of pfe Social Impact Advisors, she has managed and assessed more than $\$ 15$ billion in philanthropic resources. She has published extensively, including authoring, Good, Evil, Wicked: The Art, Science, and Business of Giving, to be published by Stanford University Press.

Ivy Johnson-Kanda has an MBA from Quinnipiac University, an MS in Food Microbiology from the University of Minnesota, and a BS in Food Science and Nutrition from the University of Ghana. She is an Adjunct Faculty at the College of Arts and Sciences, Quinnipiac University. She is also an Independent Consultant with expertise in international development, community outreach, food safety and food policy analysis, and healthcare management. She has over 13 years working experience including being a Research Scientist at the Food Research Institute, Ghana, where she became the head of Microbiology Industrial Services Unit.

\section{Introduction}

Many societal problems are beyond the scope of any one organisation to solve. In areas as diverse as climate change, education, childhood obesity, and pollution, solutions have evaded both private organisations and government agencies (Kania and Kramer, 2011). This lack of success, or even mitigation, has led to donor fatigue and frustration, creating an environment in which major funders cease funding programs. Enormous resources have been dedicated to these problems, and while there are localised improvements, there has been a little systemic success. It is also evident that international aid is being transformed at light speed by new high wealth individuals and businesses (Bronfman and Solomon, 2009). These funders have a reputation for sharp focus, innovation, and 
demanding a fast return on investment, even for complex problems such as poverty (Bishop and Green, 2008).

The demand for a fast return on investment implies a need for 'joined-up' monitoring and evaluation (M\&E) systems that not only incorporate diverse perspectives and clientele, but also focus more purposefully on inclusive results and service delivery (Yawson et al., 2006). This pressure is keenly felt in organisations leading social change programs, where funders' perceived lack of evidence about the uptake and impact of products and services calls into question the program efficacy and existence. While the impact of developmental aid and social change programs are notoriously difficult to assess, indicators of organisational effectiveness can provide reliable proxies or 'leading' indicators of developmental impact. This implies that overcoming the lack of connection between aid dollars and development impacts should not be pursued through evaluation and impact assessment studies alone but through the institutionalisation of appropriate systems like mapping the collective impact of organisations providing similar social programs, which could provide the clearest evidence of likely developmental impact.

It is evident from research outcomes that there is a need for new techniques to approach and measure advancements in addressing progress on large systemic societal issues. While there are several collaborative models available, most show limited success in addressing systemic issues. Kania and Kramer (2011) identify five major forms of collaborative efforts:

1 Funder collaborations, in which a group of funders interested in the same issue pool their resources.

2 Public-private partnerships: Partnerships between private and government organisations.

3 Multi-stakeholder initiatives: Voluntary effort from various stakeholders around a common theme.

4 Social sector networks: Ad hoc groupings of individuals and organisations with an emphasis on information sharing and short-term solutions.

5 Collective impact initiatives, long-term groupings of actors from various sectors sharing a common agenda for solving a specific societal problem.

While the other four collaborative models have had some localised success, collective impact appears to be the strategy most likely to garner long-term and significant progress addressing systemic societal problems. In this paper, we will examine collective impact as a method of maximising successes of collaborative efforts seeking to mediate or resolve systemic societal problems. We will also discuss the landscape mapping approach we developed and euphemistically named Lamisi Circle ${ }^{\mathrm{TM}}$ after the main character in our story to demonstrate how collective impact can be initiated and assessed.

\section{Collective impact defined}

The main thesis underlying the collective impact framework is that while each organisation faces a unique set of challenges because of differing levels of operations, differing visions and missions, variances in corporate culture, and the different corporate 
stories of impacts, there are also crucial commonalities. The participants of a collective impact initiative share a vision and employ common systems to address problems too large and ingrained for any single entity, even government agencies, or more ad hoc and informal groupings. Kania and Kramer (2011) define the successful collective impact collaboration as having "five conditions that together produce true alignment and lead to powerful results: a common agenda, shared measurement systems, mutually reinforcing activities, continuous communication, and backbone support organizations" (p.39). In many ways, a collective impact initiative exists as an entity separate from the many organisations contributing to the initiative. It has a vision that is shared by all participants; there is an agreed framework for measuring success in achieving that mission; participants engage in activities that further that mission through a plan which fits individual efforts into a larger schema; there is a feedback mechanism established in which all participants share information rapidly with frequent contact between participants, and a core staff exists dedicated to the initiative's mission.

Collective impact is a long-term systemic approach to some of our most difficult societal problems - wicked problems. Hanleybrown et al. (2012) write, "The complex nature of most social problems belies the idea that any single program or organization, however well managed and funded, singlehandedly can create lasting large scale change" (p.1). A properly structured collective impact initiative exists to meet a common purpose, with each participant playing a well-defined role for the initiative's success. An overarching vision exists with agreed metrics for success with robust communication and feedback and a core group of leaders who develop strategic plans for the initiative. The primary criterion for the successful collective impact initiative is unity: unity of vision - a common agenda; unity of measurements of success; unity of communications and information - continuous communication; unity of effort - mutually reinforcing activities; and finally, a unified leadership - backbone support organisations. Collective impact succeeds when deliberate leaders, dedicated, and driven people within developed organisations pool their strengths to tackle large and systemic issues beyond the scope and capacity of any one organisation, or even governmental agencies (Peterson et al., 2018). These problems are so large, with so many different issues contributing to them that it is nearly impossible for any single organisation to successfully address them.

\subsection{Common agenda}

The concept and practice of defining a common agenda elevate the outcome of collective impact immensely. It is necessary to understand that collective impact is "not just a fancy name for collaboration, but represents a fundamentally different, more disciplined, and higher performing approach to achieving large scale social impact" [Hanleybrown et al., (2012), p.2]. Identifying the skills, culture and motivations of each partnering organisation will allow for all resources to be used to their capacity (Yawson and Greiman, 2016). In all, a common agenda serves as the tool to agree on "shared visions for change including a common understanding of the problem and a joint approach to solving it through agreed upon actions" [Hanleybrown et al., (2012), p.2]. "Establishing a common agenda is two-fold; requiring the creation of boundaries within social issues and the actions necessary to address them and the developing of strategic action framework to guide the activities of the initiative" [Hanleybrown et al., (2012), p.4]. 


\subsection{Shared measurement systems}

Community collaborative initiatives emerge out of a desire to address complex social needs (Peterson et al., 2018). Starting with the joint development of a common agenda means everyone gains a common understanding of the problem. However, it is not enough to simply identify the problem and establish a roadmap for success without a measurement system that tracks progress. Data and measurement are essential ingredients of the collective impact strategy. The shared measurement system component of collective impact requires that all of the participants work towards the same goal and measure the same data. Data can be used in these initiatives as the neutral information by which the collaborative participants can base their lessons learned from the implementation of coordinated actions, and allow multiple players to work towards solving critical social issues (Peterson et al., 2018).

Hanleybrown et al. (2012) define shared measurement as the "use of a common set of measures to monitor performance, track progress towards outcomes and learn what is and is not working in the group's collective approach" (p.5). The benefits of using shared measurement systems to support collective impact include improving data quality; tracking progress towards shared goals; enabling coordination, alignment, and collaboration; learning and improving implementation based on feedback; and spurring action (Kramer et al., 2009).

Of the five conditions for collective impact, shared measurement is the most difficult to implement and achieve results. It is a daunting task to meet with a group of different cross-sector organisations and agree on program indicators, goals, and outcomes. Few have mastered the partnership aspect of the work, and even fewer can produce outcomes that capture the essence of the work. Typically evaluations focus on an individual organisation's impact and funders also expect reports that describe the gains within a small and specific population. Funders must be willing to allow the grantees to develop and improve the work as a collective by abandoning typical individual expectations. The funders must also be willing to provide some unrestricted funds to support the collaborative efforts. Kramer and Kania (2011) write, "Funders must help create and sustain the collective processes, measurement reporting systems, and community leadership that enable cross-sector coalitions to arise and thrive" (p.41).

\subsection{Mutually reinforcing activities}

There is a proven correlation between establishing a common agenda and executing mutually reinforcing activities (Romme and Dillen, 1997). "To be successful in collective impact efforts, we must live with the paradox of combining intentionally (that comes with the development of a common agenda) and emergence (that unfolds through collective seeing, learning and doing)" [Kania and Kramer, (2013), p.7]. Non-profits utilise the collective impact strategy to approach social problems in three reinforcing activity frameworks: multi-problem individuals, multi-faceted problems and a combination of both. Multi-problem individuals are those faced with harmful effects of multiple social issues and must have interventions simultaneously to one another to establish progress; multi-faceted problems focus on aiding targets over time through the context of one social issue. With this said, a combination of these approaches would include a coalition addressing multiple social issues over the course of time. Through diverse approaches, 
participants in collective impact must contribute through actions that exercise their strengths while supporting their overall agenda.

\subsection{Continuous communication}

Continuous communication among participants is a critical factor to the success of a collective impact initiative. According to Kania and Kramer (2011), "Participants need several years of regular meetings to build up enough experience with each other to recognize and appreciate the common motivation behind their different efforts" (p.40). Continuous communication is an evolutionary process that reflects the years of effort toward building trustworthy relationships and expressing appreciation for the interests and efforts of diverse participants which help to facilitate the common agenda (Kania and Kramer, 2011; Ledley et al., 2014). There are inherent communication obstacles when meshing together diverse participants with varying interests. From the inception of the initiative, participants must actively work to develop a 'common language' (Kania and Kramer, 2011) that reflects the 'needs and values of all stakeholders' (Ledley et al., 2014). The use of a common language helps to ensure that participants agree on the collective agenda, objectives, and measurements of success. Kania and Kramer (2011) observe that even this process takes time, citing the Strive Together collective impact initiative to support education, whose networks have been 'meeting regularly for more than three years' (Kania and Kramer, 2011). Despite how long the process may take, the development of a common language is regarded as an 'essential prerequisite to developing shared measurement systems', which are another hallmark of collective impact initiatives (Kania and Kramer, 2011).

A phenomenon known as the silo effect can also occur, where participants who are brought together to collaborate maintain their 'inwardly' focus and where 'external relationships are given insufficient attention' (Vatanpour et al., 2013). Vatanpour et al. (2013) describe the silo effect, as "breakdowns in communication, cooperation between unit participants and other stakeholders, and the development of fragmented behavior, are common features" (p.209). To combat this effect, the backbone organisation should enable and support open communication lines between participants. A sharp focus on extending communication beyond regularly scheduled meetings will afford participants the opportunity to continually share knowledge and work together to solve common problems (Kania and Kramer, 2011). A 2012 Government Accountability Office report also shows that open communication lines help the staff of an inter-agency project 'establish positive relationships' and 'brought greater focus' to their shared agendas (Government Accountability Office, 2013, 2014). Some examples of successful open communication facilitators include the use of task forces, shared data reporting mechanisms that show progress among participants, teleconferences, in-person conferences and retreats, web-based 'hang-outs' where participants can log in, chat and post updates, and the distribution of newsletters and e-mail blasts (Kania and Kramer, 2011; Ledley et al., 2014; Wiley et al., 2013).

\subsection{Backbone support organisations}

Backbone support is one of the key components to executing a successful collective impact strategy. The complex structural elements of collective impact involve the alignment and coordination of many different organisations. Kania and Kramer (2011) 
define backbone support as "a separate organization(s) with staff and a specific set of skills to serve as the backbone for the entire initiative and coordinate participating organizations and agencies"(p.2). This dedicated set of resources is tasked with providing the overarching support, strategy and coordination for the entire initiative and can be structured in various ways depending on the issue, geography, and specific situation. Failure to sufficiently resource and fund this supporting infrastructure has also been identified as one of most frequent reasons why collective impact initiatives do not succeed (Kania and Kramer, 2011).

A potential roadblock to building effective backbone organisations is funding. A backbone organisation's funding can be less than $1 \%$ of the total budget of organisations they support, yet can also be seen as the type of expense and overhead that funders want to avoid. Funders are more apt to fund specific short-term interventions than an openended process that contributes to sustainable social impact over many years (Bishop and Green, 2008).

\section{Collective impact landscape mapping}

By creating a model of the ecosystem of organisations around a particular issue, the funder can understand who else is working in the same space, identify potential allies, and anticipate political or economic challenges that might arise (Peterson et al., 2018). This is the foundation of any collective impact initiative. Mapping the constellation of organisations helps a new entrant visualise potential partners and helps a funder understand the landscape in which it will operate and create the basis for any collective impact initiative. Even if a map does not completely represent every stakeholder around the issue, by creating or visualising such a chart, funders can think expansively about the context in which their work occurs and create a context of work relating to the issue being addressed that also identifies potential but unusual advocates and allies.

Collective impact discussions and initiatives have focused on the partnerships between various entities - corporations, international NGOs, multilateral agencies, local funders, and international foundations, and the power they yield in social change initiatives and developmental impact. Yet, the heart and soul of good work are helping the disadvantaged, especially the world's poor. If we flip the centre and focus on the bottom billion - people living on less than a $\$ 1$ per day, most of them being women and children - the perspective is very different. There is, therefore, the need for what we call the 'dialogue at the interface' where these two systems collide. There is, therefore, the need for what we call the 'dialogue at the interface' where these two systems collide at the intersection of the top trillion and the bottom billion. The top trillion are the funders with trillions of wealth and the bottom billion being those billions of world population living on less than a dollar a day, and at the interface of these colliding systems is where the dialogue of collective impact should occur.

\subsection{The underlying thesis of collective impact landscape mapping}

The main thesis underlying the construction of Landscape Maps (Lamisi Circles ${ }^{\mathrm{TM}}$ ) is that while each organisation faces a unique set of challenges because of differing levels of operations, differing visions and missions, variances in corporate culture, and the 
different corporate stories of impacts, there are also crucial commonalities. In the end, it is the collective impact of the activities of all the players in that respective landscape on the poor is what matters. No organisation is an island; every organisation is in a system with other players. It is, therefore, important to build peer networks, both formal and informal, to help individuals, their institutions, and the larger field achieve greater impact.

\subsubsection{Conceptual framework}

The development of the landscape maps is situated in systems, complexity, and stakeholder theories (Yawson and Greiman, 2014). We also contend that linear epistemology as the dominant epistemology in grantmaking, poverty alleviation, impact evaluation, and development, in general, can no longer be the dominant epistemology. With this underlying theoretical framework, we approach our mapping analysis based on the wicked problem construct and the Deliberate Leadership ${ }^{\circledR}$ framework (Peterson et al., 2018).

Figure 1 Lamisi's human security (see online version for colours)

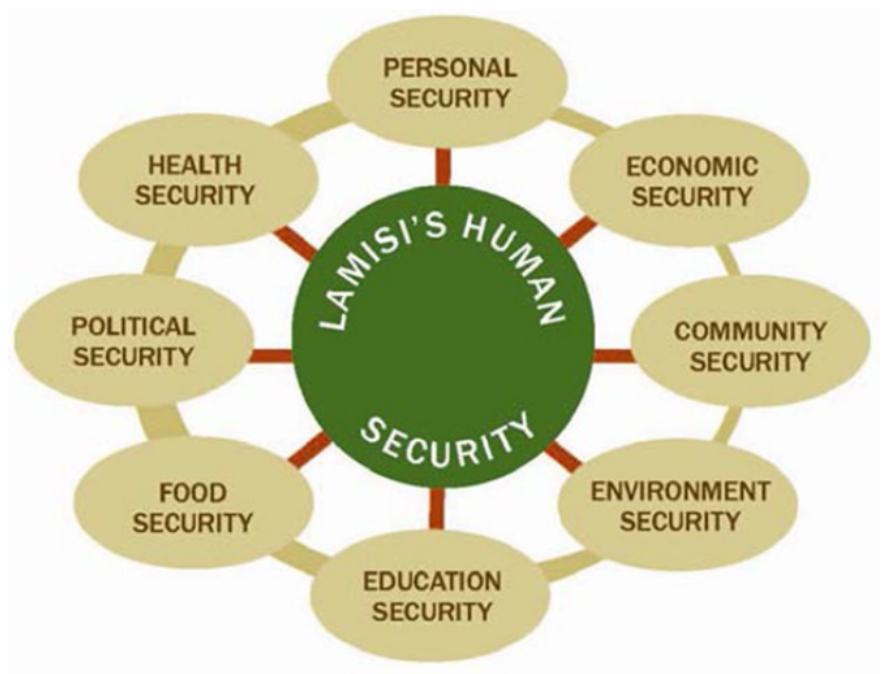

(C) 2018 pfc Social Impact Advisors

In developing the maps, we use the dimensions of the UN Human security frame as our unit of analysis. Using the dimensions of human security - community, economic, educational, environmental, food, health, personal, and political, we describe holistically the human security dimensions in the particular landscape to understand the universe in which the specific grantmaker/funder operates and the intersections that exist. Building a holistic view is important because increases in security at one dimension do not replace nor eliminate demands at other dimensions. On the contrary, insecurity at one of the eight dimensions affects the other dimensions. Understanding the human security as greater 
than the sum of its parts imply better coordination between dimensions and help in developing more sustainable funding and collective impact framework and policies to address the wicked problems at the intersection of the various dimensions. Figure 1 is diagrammatic depiction of the dimensions of Lamisi's human security.

\subsubsection{Human security framework}

Human security is a wide-ranging concept that demonstrates the weaknesses and vulnerabilities of human beings, as well as their potential (Johnson-Kanda and Yawson, 2018). It is the interface where the two systems of top trillion and the bottom billion collide. That is where the dialogue at the interface occurs, and opportunities for growth and development are increasingly linked, yet can become sources of insecurity (Onuoha, 2009). This is important both for understanding the sources of such threats to human life and for providing strategies to address them. Intended to encompass freedom from fear (violence) as well as freedom from want (poverty), human security is a multidimensional construct that represents a shift from notions of security that are nation-centred to one that is people-centred (UNDP, 1994). Protection of national borders is irrelevant to threats that lie within them (e.g., genocide, terrorism) as well as those that lie without (e.g., global warming, nuclear holocaust). No human security index comparable to the Human Development Index currently exists, and data that are available for some of the individual dimensions are typically not disaggregated by sex. While yet to be fully operationalised, the UN Human Development Report identified seven dimensions required for human security: economic security, food security, health security, environmental security, personal security, community security, political security (UNDP, 1994). In this paper we included an eight dimension - education security.

\subsection{Method of analysis}

The mapping analysis involves comprehensive desk research, interviews, lived experiences, storytelling, and personal communication. Using existing databases notably the UN database on NGOs, and international and country databases all the players in the landscape under consideration are listed. Depending on the scope of the map, specific criteria are developed to include and exclude the players that will appear on the map. In developing the landscape map in Lamisi's universe to illustrate the interconnectedness of issues, we grouped the organisations into eight categories drawn from the UN Human security frame and our added dimension - educational security (Peterson, 2009). These include the basic needs of the world's most vulnerable for food, physical security, education, health, economic security, political safety, environmental safety, and a healthy community. After all the players are mapped, metadata is created for each of the listed players. The metadata may include the following attributes: characterisation under the various dimensions of the HSF; assets; notable programs; contact information (e-mail, websites, phone fax, mailing address, physical address); contact person; mission statement; among others. The metadata is used in building the collective impact framework of common agenda, shared measurement systems, mutually reinforcing activities, continuous communication, and backbone support. 


\section{Bottom-up approach to collective impact - the story of Lamisi Seidu}

Through the life of Lamisi Seidu, a typical, poor, rural Ghanaian woman, we tell the symbolic story of poor women living in rural, peri-urban, and urban areas all over the world. The story of Lamisi Seidu as presented in this manuscript is taken in its entirety from a report produced by pfc Social Impact Advisors (Peterson, 2009).

Lamisi and women like her live at the interface of what the United Nations and others call the dimensions of human security: economic, food, health, educational, environmental, community, political, and personal (UNDP, 1994; Peterson, 2009; Johnson-Kanda and Yawson, 2018). These security dimensions are the intervention points from which the first universe of philanthropy and funders (non-profit organisations, corporations, private foundations, or government sources) interact and enter into Lamisi's women-centred universe. The tale of Lamisi helps us to understand how the challenges and opportunities for the universe of philanthropy, (the top trillion) can meaningfully and respectfully help women like Lamisi (the bottom billion) achieve a better life. Acs and Dana (2001, p.64) define philanthropy as "the voluntary and unconditional redistribution of wealth, by the private sector; donors share their wealth, thereby causing a one-way transfer of wealth." While this definition has stood the test of time, it tells the story of only one part of the philanthropic universe - the top trillion. The bottom billion which forms the other part of the philanthropic universe is not adequately captured. There is the need for dialogue at the interface of the colliding systems of philanthropy.

Storytelling is a powerful research method and aids the development of personal resilience and provides opportunities to celebrate the hardiness of research participants who contribute to knowledge by recounting their stories of difficulty and adversity (Kramer et al., 2009; Osafo and Yawson, 2017).

\subsection{The story of Lamisi Seidu}

It is daybreak. The only sounds in the small hut are those of steady breathing. With her eyes still closed, the woman lying on the straw mat pauses a moment to rub her stiff right arm, then winces with the constant pain she feels in her lower abdomen as she tries to rise. Sometimes she feels this pain when carrying her children on her back, lifting foodstuffs or firewood to her head, bending over to work in the fields or lifting a container to fetch water from the distant well. This 'hurt' is something she has felt since the birth of her last child. She has learned to live with it. Slowly, she opens her eyes to scan those around her: her husband, not stirring; her children, two girls and three boys, ages 18 months to 14 years, peaceful in their slumber. Within seconds, she is on her feet. She washes her face and quickly lights the firewood for cooking. The family awakens slowly to the sounds of the crackling fire and the soft voices of other village women who also have started their day.

Thus begins another cycle in the life of Lamisi Seidu, a 38-year-old woman who lives in the Talensi-Nabdam District in the Upper East Region, one of the poorest and most remote districts in the West African Republic of Ghana. Lamisi's day is filled with constant physical toil: lifting, carrying water, cooking, washing, tilling the fields, walking with bundles, caring for her children, and tending to the needs of everyone in her family. Her primary focus is to feed and care for her family. Her day ends far into the night when 
she returns again to the mat on the floor of her hut for sleep, only to start the cycle all over again at the next daybreak.

This is her life, the only one she knows, and the only one she likely will ever know. It is the universe of women in Sub-Saharan Africa, where women produce up to $80 \%$ of basic foodstuffs and do up to three-quarters of all agriculture work in addition to their domestic responsibilities. They only deviate from this routine when they go to get salt and kerosene from the market. Figure 2 chronicles a typical day for Lamisi and other women like her.

Figure 2 A typical day for Lamisi and other women like her (see online version for colours)

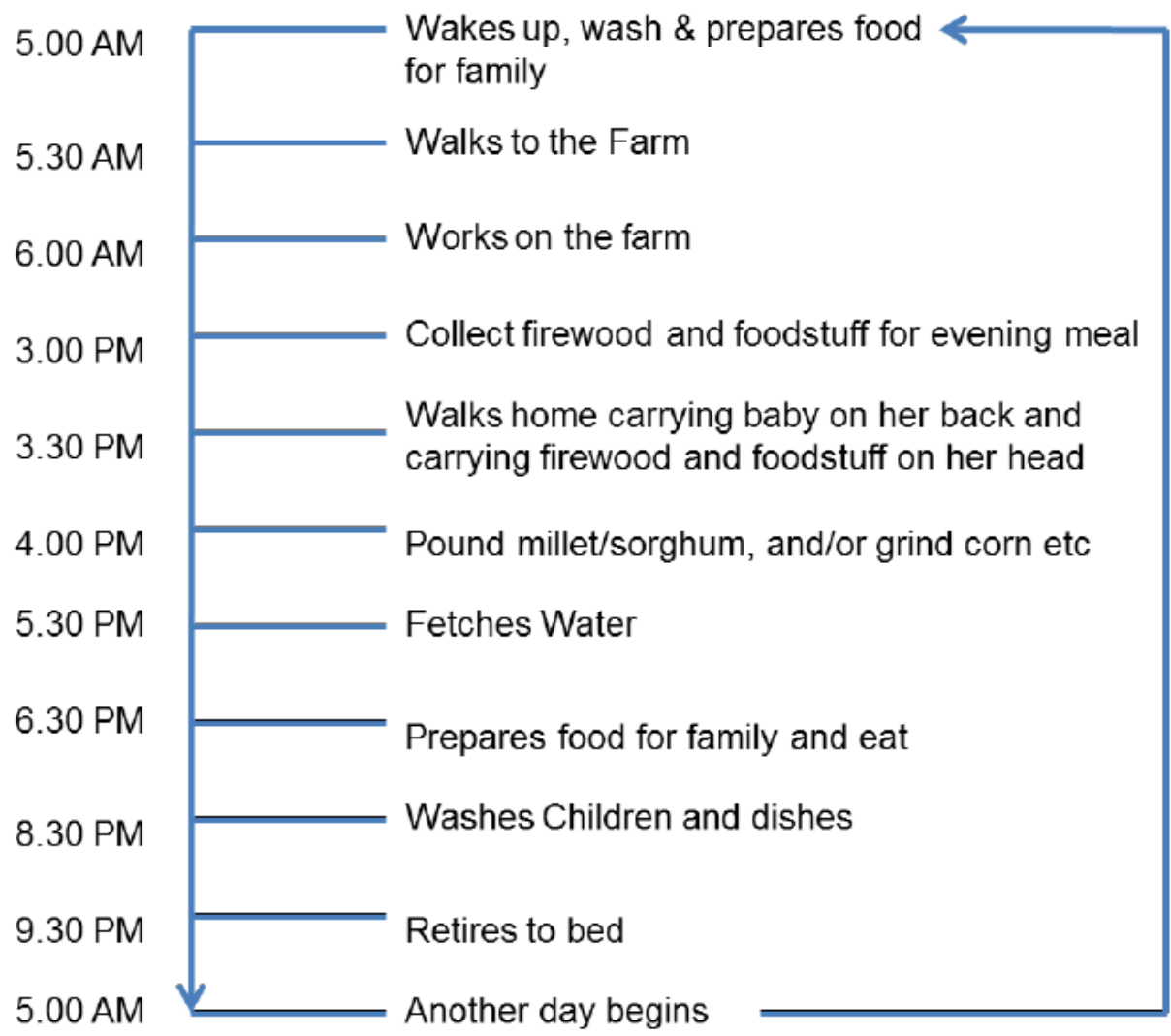

A woman with no formal education, Lamisi was married at age 24 to a man who is sometimes abusive. It is a monogamous marriage. Her husband works on the family farm and is the chief messenger for the village chief. Two of her sons, ages twelve and eight, are in primary school, and two other children, a boy, and a girl, are four years and eighteen months respectively. The fifth and eldest, a girl, has completed primary school and will get no further education by dictate of her father and grandmother. Lamisi has had two additional children who died at birth. Lamisi's body is not her own. It is a vessel for work and reproduction. She has no control over her pregnancies or any other health issues for herself and her family. The 'keepers' of her body are her mother-in-law, who lives five huts away, and her husband, who controls the economics. Her mother-in-law 
gives advice, mediates with her son for how monies will be used and discusses Lamisi's health concerns with her.

Theirs are the dominant voices in the family. Lamisi's voice and those of other women in the village remain silent because of the complex and culturally defined hierarchy of communication particular to rural Ghanaian culture. This rigidly prescribed hierarchy of communication prevents her from seeking help outside the family, and although non-family members have offered to help, it also imposes restrictions on her ability to accept assistance. In fact, Lamisi's loss of two children at birth was due to her family's culturally-embedded beliefs and practices surrounding prolonged labour. Her husband prevented her from seeking medical help until the family consulted with its ancestors to determine the cause of the long labour. Only then were steps taken to ensure a safe delivery. Furthermore, cultural practices dictated that Lamisi was not permitted to know the outcome of the consultations.

Lamisi's total economic dependence on her husband serves as an additional obstacle in seeking care for her and her family's health needs. Because of this dependence, her ability to obtain healthcare is limited, whether trying to access more expensive, modern healthcare services or the less costly services of traditional healers. Moreover, the nearest healthcare facility is $22 \mathrm{~km}$ away and is accessible only on market days when she can join the vehicles taking produce and other items to market. Ultimately, Lamisi is thwarted by factors beyond her control: socio-cultural norms, beliefs, and practices; family influences; socio-economic issues; the nature of the healthcare system; healthcare providers' attitudes, particularly nurses; and the community of gossip.

It is common knowledge that nurses who represent the healthcare systems in rural Ghana relate to poor rural women in ways that mirror the larger societal devaluation of women. At health centres in rural Ghana, poor rural women, even pregnant ones, stand as a sign of subordination when speaking to nurses. This attitude is insidious; nurses scold and treat women in Lamisi's universe like children. Fear of gossip is also a powerful deterrent to rural women seeking healthcare about reproductive issues. The fear is intense and centres on being judged negatively or mocked by the community for falling outside of acceptable cultural behaviour. One fears being ridiculed - either for getting pregnant or failing to get pregnant at the right time. And because Lamisi must yield to the family as gate-keeper, her health and that of her children are compromised.

The story of Lamisi is a classic example of wicked problem, where conflicting issues emerge, creating a complex web of interdependencies that negate a simple solution. This further complicates how impact is seen, assessed and measured. To illustrate the interconnectedness of issues, and to assess the collective impact of the top trillion on Lamisi, we developed a landscape map of all the organisations in Lamisi's constellation.

\section{The Lamisi Circle}

This section gives the overview of the landscape map developed to assess the collective impacts of organisations in Lamisi's universe. Adding educational security to the United Nations Seven dimensions of human security - community, economic, environmental, food, health, personal, and political, we describe intersection points between social change programs by the top trillion and the realities with which Lamisi and her sisters in the bottom billion cope each day. 


\subsection{Wicked problems: Lamisi's human security}

As the intersections occur, wicked problems emerge within and between the funders at the top who try to provide stability and sustainability and the poor in the bottom billion who are the recipients. Here are the dimensions of Lamisi's human security, noting some of the funders who are attempting solutions.

\subsubsection{Community security}

Lamisi's community is very close knit with a population of about 500 . She participates in monthly community labour projects and attends funerals and other social gatherings. Everyone keeps an eye out for their neighbour's welfare. But this is not enough. Her village is constantly being raided by Fulani herdsmen. The nearest police station to Lamisi's village is $58 \mathrm{~km}$ by way of an almost impassable road.

\subsubsection{Economic security}

Lamisi has no economic security. Because of her role in the family, she has limited control over family property and household financial resources and no access to credit from financial institutions. Although there are several micro-credit initiatives in her area, economic stability is almost non-existent in Lamisi's life. In trying to survive, Lamisi's family must face other challenges - illegal mining and child labour. Although neither Lamisi nor any of her family is involved in these mining activities. It represents another risk to her two sons, who are currently in primary school and may join the steady stream of children leaving school to work as labourers. Over the past two decades, the Talensi-Nabdam District has experienced a rapid and unprecedented upsurge in artisanal mining (gold and precious metals) and illegal mining (galamsey) activities. Mining creates significant environmental, health, and safety concerns. It also creates the atmosphere for widespread prostitution, significant disease such as HIV/AIDS, and widespread child labour involving boys and girls of all ages. The deplorable conditions in which many of these children in the district work caught the attention of ILO officials and led to the launch of 'operation sunlight' where a CBO (Afrikids) was tasked to rehabilitate 150 children. Unfortunately, the program was not financially sustainable.

\subsubsection{Educational security}

Education is a proven way out of poverty for women and girls, but even this presents a wicked problem. On the surface, it might appear that the education of Lamisi's daughter was halted for economic reasons. It is more likely that the family ended the girl's schooling because she entered puberty and began her menses. This wicked problem is one where many issues intersect for Lamisi and her daughter and where aid (from a non-profit organisation, corporation, private foundations, or government sources) could change the girl's life by providing her with a simple way to continue her education: sanitary pads. In a study by the University of Oxford on the 'Impact of providing sanitary pads to poor girls in Africa,' findings show that the onset of menses goes beyond stopping a poor girl's education and can result in a health and safety issue. The study explains that menarche brings an array of negative practices, including sexual harassment, withdrawal of economic support from home, sudden pressure to marry or 
take a boyfriend, pressure to leave home, and possibly falling into prostitution or slavery. But the wicked problem does not stop here. There is an additional problem of what to do with the pink plastic wraps around the sanitary pads. They are not bio-degradable and can harm the environment, thereby challenging the manufacturer to develop a 'green' method of disposing of wrappings. As this example illustrates, the intersections of the two universes, the top trillion in philanthropy and those in the bottom billion, can expose wicked problems that extend beyond what is immediately apparent in a situation.

\subsubsection{Environmental security}

Changes in Lamisi's natural environment are making life harder. Desertification is becoming a serious issue and is the result of poor agronomic practices, such as cutting trees and shrubs for firewood, bush burning, and overgrazing as well as the effects of global climate change. Lamisi also has no direct access to potable water and has to travel $2 \mathrm{~km}$ to fetch water from a stream or $3 \mathrm{~km}$ to get potable water from wells built by charitable organisations such as Churches of Christ Foundation (CCF) and NGOs, such as WaterAid, ADRA, ActionAid, and Plan (Ghana). There have been many interventions in Lamisi's universe by several NGOs to help stem the tide of environmental degradation. Although there are a number of NGOs and CBOs involved in environmental programs, there is limited coordination and weak collaboration among them. Research, action, targeted strategies, and public awareness regarding the differential impacts and implications of environmental problems for women like Lamisi remain limited. The government-led efforts to use liquefied petroleum gas (LPG) and kerosene stoves instead of trees and shrubs for fuel has been largely unsuccessful. Any attempt to help Lamisi understand the implications of global climate change is a wicked problem. She is too busy thinking about the next meal for her family.

\subsubsection{Food security}

Lamisi and her family are vulnerable to food insecurity because of severe difficulties in the production of food for home consumption and access to marketed food. Her household experiences about five months of food insecurity annually. The family either is unable to produce enough food to last throughout the year or is unable to store enough for home consumption. During these insecure food periods, Lamisi's household uses a wide range of ways to survive: They collect wild foods, buy food at the market, participate in in-kind (food) payments, get support from relatives and friends, and sell livestock and household valuables. They also reduce the number of meals served each day, the portions/sizes of meals, and consume less-preferred foods. There are dozens of NGOs and CBOs in Lamisi's universe with a goal of alleviating poverty through improved agricultural productivity. The major funders of these activities include the UK's Department for International Development (DFID) through its Crop Postharvest Programme and other initiatives; USAID; and the Gates Foundation, among others. 


\subsubsection{Health security}

Although the Government of Ghana has implemented free maternal care for all pregnant women, in all of her seven pregnancies, Lamisi did not visit a healthcare facility nor were any of her children born in a healthcare centre. Only her last child received a polio vaccination, even though vaccinations are free. Lamisi's experience and that of other poor Ghanaian women seeking healthcare is a wicked problem. In addition to factors cited earlier, she also experiences a lack of available transportation, high transportation costs, and poor road conditions. A shortage of trained healthcare staff is also significant, especially for those living in remote areas. As of 2005, the entire Talensi-Nabdam District, with a population of 100,789, had only one medical doctor and 20 nurses. The other service providers were 55 traditional healers and 60 traditional birth attendees (TBAs).

\subsubsection{Personal security}

Lamisi's personal security is not in danger from those in her village, but there is a tendency for her husband to be abusive. Even more devastating, Lamisi, like $75 \%$ of her rural sisters in the Upper East, has experienced female genital mutilation, despite the fact that Ghanaian law prohibits the practice. It is estimated that more than 135 million African girls and women have been mutilated which causes long-term pain and illness.

\subsubsection{Political security}

For now, Lamisi has political security. Every two years politicians come into Lamisi's village to solicit her vote for national or district elections. Nobody harasses her because of her political views, which are almost always those of the village chief. Working through some CBOs and political parties, the National Commission for Civic Education has created a political awareness in her. Since Ghana's return to democracy in 1992, there has been the steady empowerment of women in politics, especially women in local politics.

\subsection{Landscape maps of Lamisi's universe}

There is a web of organisations - NGOS, CBOs, foundations, aid agencies from around the world - directly working in the Talensi District each trying to change Lamisi's life. To assess the impact of these organisations on the life of Lamisi and her children and for any successful collective impact initiative, there is the need for mapping of these organisations in the Landscape. Figure 3 is the landscape map of organisations impacting Lamisi's human security. 
Figure 3 Organisations impacting Lamisi's human security (see online version for colours)

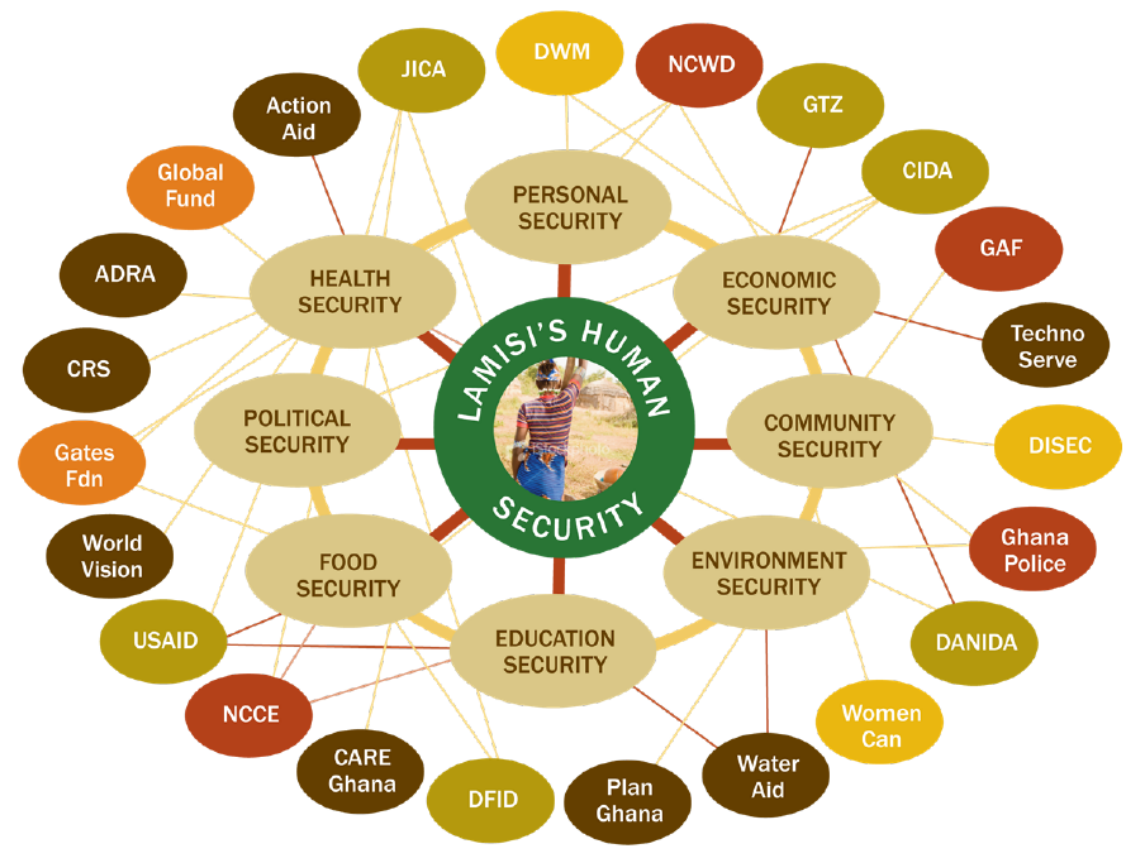

(C) 2018 pfc Social Impact Advisors

As at 2010, conservative estimates put the number of both local and foreign NGOs in Ghana at 1,500 with approximately 30 NGOs focusing specifically on the needs of women and girls. Major funders that support NGOs and CBOs impacting Lamisi's universe, as well as women and children throughout Ghana, include the alphabet soup of aid and development organisations: USAID (United States Agency for International Development), DFID (UK's Department For International Development), DANIDA (Danish International Development Agency), CIDA (Canadian International Development Agency), SNV (Netherlands Development Organisation), GTZ (German Technical Cooperation Agency), AfDB (African Development Bank), FAO (United Nation's Food and Agriculture Organization), IFAD (International Fund for Agricultural Development), IFC (International Finance Corporation), ILO (International Labour Organization), IMF (International Monetary Fund), UNCTAD (United Nations Conference on Trade and Development), UNDP (United Nations Development Programme), UNESCO (United Nations Educational, Scientific and Cultural Organization), UNHCR (United Nations High Commissioner for Human Rights), UNICEF (United Nations Children's Fund), UNIDO (United Nations Industrial Development Organization), WHO (World Health Organization), among several others. Additional funder support includes foundations/trusts (foreign), intermediaries, corporations, Diaspora remittances, and religious organisations. Figure 4 shows the intersection of these various organisations seeking to impact Lamisi and her 'sisters' throughout Ghana. 
Figure 4 Ghanaian women human security constellation (see online version for colours)

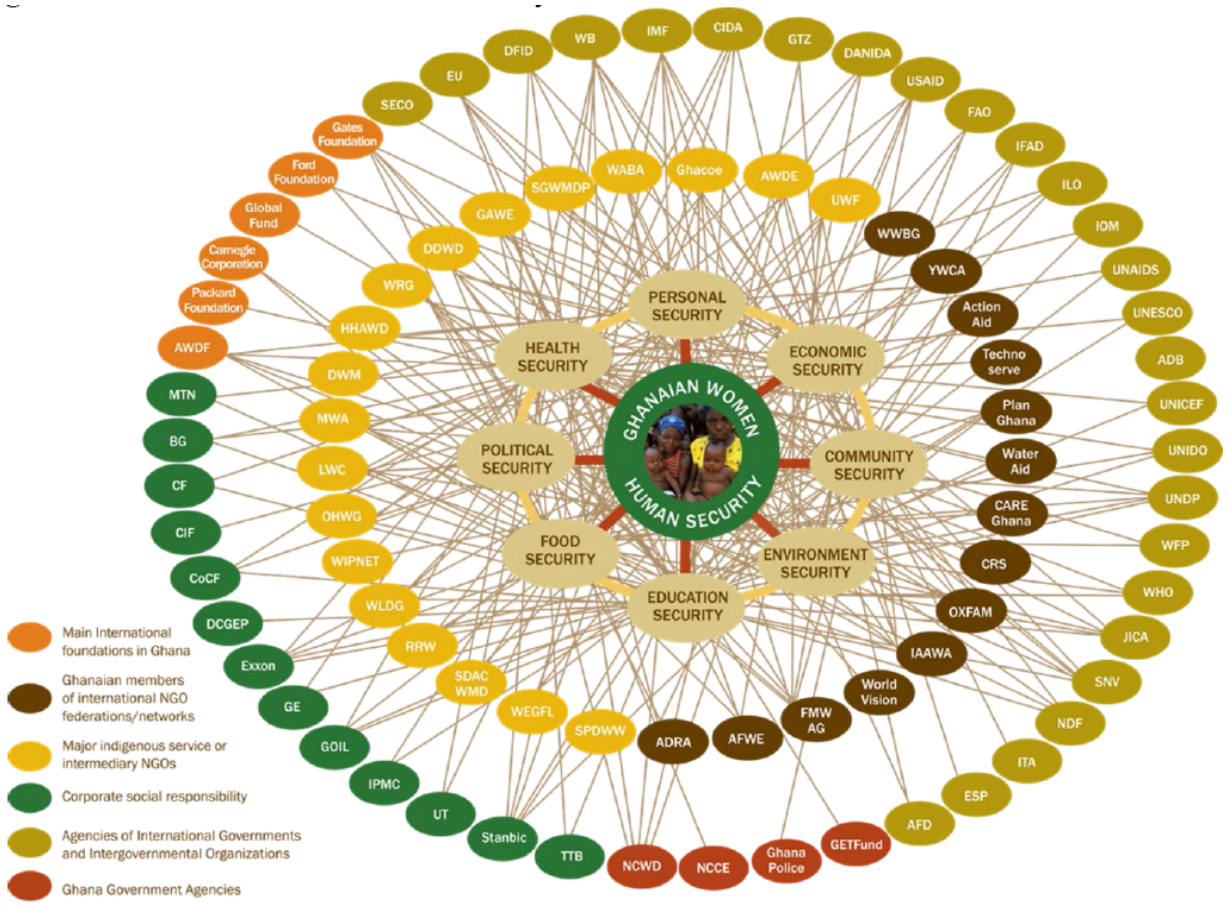

(C) 2018 pfc Social Impact Advisors

\section{A precarious intersection between the top trillion and bottom billion}

There are many challenges, constraints, and opportunities at the interface of the funder-centric universe and Lamisi's woman-centred universe. As philanthropists in the top trillion seek to improve the lives of the bottom billion, they must honestly address the challenges with candor to have the greatest impact and to achieve the good they seek. Some of these issues include:

- Lamisi has little voice in how funders and NGOs want to improve her universe. She is restricted from providing information on how best she could be helped and what she needs.

- Many foundations do not collaborate or coordinate their grantmaking, thereby making it difficult to understand the positive and negative impacts of funding and the thus the call for collective impact initiatives (Worth, 2017). However, the five conditions of collective impact, implemented without attention to equity, are not enough to create lasting change (Kania and Kramer, 2015). "If participants in collective impact initiatives are to make the lasting change they seek, they must pay explicit attention to policies, practices, and culture that are reinforcing patterns of inequity in the community." [Kania and Kramer, (2015), p.2] 
- Moreover, cooperation is constrained between local NGOs and foreign philanthropists and funders by foreign-dominated aid regimes and their models and priorities. Local NGOs are often excluded from the process of establishing funding priorities and are projected into roles determined by outside actors.

- NGOs duplicate government service programs, except in scale, and do not build long-term capacity of communities and organisations to become self-sufficient. NGOs tend to provide support related to welfare programs and relief aid rather than skills training, credit assistance, and institution-building.

- NGO language is incongruent with Lamisi's culture and understanding. The NGOs working directly in Lamisi's universe, like their global counterparts, have incorporated into their vocabulary notions about 'participation', 'empowerment', and 'sustainability'. What do these concepts mean in practice in Lamisi's universe? Who translates between the two universes? There is a need for a dialogue at this interface.

- The notions of development and development intervention are areas of negotiations; Lamisi is left out of the conversation.

- $\quad$ The wicked problems in Lamisi's life are either ignored or the complexity misunderstood by funders, NGOs, and aid providers. They tend to focus on one or two aspects rather than on the whole. Also, there is a lack of coordination and collaboration in providing services and understanding the unintended consequences. Although all of these NGOs and funders are important players in the mix of institutions concerned with Lamisi's social and economic development, the nature and organisation of their activities also raise problems and challenges.

- Concerns about long-term sustainability for programs as NGOs relieve government by providing safety nets in Lamisi's universe.

- Lack of coordination and coherence of NGOs activities in the broader network of institutions involved in development.

- Donors and funders engage in a de facto social policy with little scrutiny and regulation. There is concern about a growing loss of local control of social policies and programs because of a growing imbalance between donors and Ghana's government and who has influence over said policy.

- Concerns over funder 'fickleness' and disintegration of NGO and support when their foundation or program areas and create devastating consequences.

\section{Conclusions}

Collective impact seeks to address long-standing societal problems (wicked problems) that have been stubbornly persistent despite decades of effort and billions of dollars spent. We have discussed numerous issues with implementing a successful collective impact initiative, including roadblocks and hurdles in building systems that address the five core criteria of collective impact: a common agenda, shared measurement systems, mutually reinforcing activities, continuous communication, and backbone support organisations. These challenges can certainly be overcome, but there is a cost in effort, 
time, and money. Poorly designed collective impact initiatives waste valuable resources and funding as the participating organisations work at cross purposes because of some failure of design or implementation.

Properly designed and implemented collective impact initiatives can create longlasting positive effects (Stachowiak and Gase, 2018). The collaborative effort of disparate groups, with differing skill sets and resources, can create synergies leading to progress that is beyond what any single group could achieve. The challenge is recognising when a problem is large and complex enough to warrant the significant upfront costs in designing the systems necessary for a collective impact initiative to flourish. Poorly designed initiatives, or ones that would be better handled by single organisations or more ad hoc collaborations, create an inefficient and ineffective model for the collective impact strategy. Well-designed initiatives utilising the Lamisi Circle ${ }^{\mathrm{TM}}$ concept will help address these challenges. To maximise the effectiveness of the top trillion's impact on Lamisi's and the bottom billion, several questions must be explored. Questions to begin the conversation include:

- How can these universes together begin to address wicked problems at many levels and achieve lasting change in a respectful, ethical, and effective way?

- How can a culture of candor, collaboration, and robust learning be created across givers, receivers, and advocates - from Lamisi and her Ghanaian sisters, NGOs, large and small foundations, aid organisations, and the private sector?

- How can all funders live by do-no-harm principles deeply embedded in ethics, values, and culture?

- How can a web of issues and the diversity of voices be at the table and on-the-ground to achieve lasting positive change?

- How are power dynamics equalised and authentic woman and community voice and solutions created and implemented?

- What are the cultural, programmatic, and organisational shifts that need to be made to ensure that the principles of international grantmaking can be lived and expanded upon as needed?

- How can the web of organisations working for change be mapped and coordinated and analyzed to understand impact and strategies tried and emerging best practices?

- Have funders made a difference in the lives of those whom they seek to serve including helping to positively address gender and class relations in society?

It is clear. There are no simple solutions for improving the quality of life for Lamisi Seidu and her children. Despite the best efforts of NGOs, CBOs, foundations, religious organisations, government projects, and well-intentioned individuals who try to improve her human security, wicked problems remain. The unrecognised issues from which there is no escape will always reveal themselves at the intersection points between the funders in the top trillion and the poor in the bottom billion. The challenge is how to meld the two universes to create better solutions even when the scope of the solutions may be limited. A collective impact approach based on the principles delineated in this paper can be one way of addressing these challenges at the interface. And while the doers and thinkers in their universe ponder their choices, for now, little really changes in Lamisi Seidu's life. 
She rises each morning at dawn in her hut in rural Ghana, listens to the steady breathing of her sleeping family, feels the pain in her body, and remains silent in her universe, with her only thought being how she will feed her family for that day.

\section{References}

Acs, Z.J. and Dana, L.P. (2001) 'Contrasting two models of wealth redistribution', Small Business Economics, Vol. 16, No. 2, pp.63-74 [online] https://doi.org/10.1023/A:1011128000647.

Bishop, M. and Green, M. (2008) Philanthrocapitalism: How the Rich Can Save the World, Bloomsbury Publishing, New York, NY.

Bronfman, C. and Solomon, J. (2009) The Art of Giving: Where the Soul Meets a Business Plan, John Wiley \& Sons, New York, NY.

Government Accountability Office (2013) Managing for Results: Key Considerations for Implementing Interagency Collaborative Mechanisms (GAO-12-102), U.S. Government Accountability Office, Washington DC.

Government Accountability Office (2014) Managing for Results: Implementation Approaches Used to Enhance Collaboration in Interagency Groups (GAO-14-220), U.S. Government Accountability Office, Washington DC.

Hanleybrown, F., Kania, J. and Kramer, M. (2012) 'Channeling change: making collective impact work', Stanford Social Innovation Review, January, Vol. 9, pp.1-8 [online] http://www.ssireview.org/pdf/Channeling_Change_PDF.pdf.

Johnson-Kanda, I. and Yawson, R.M. (2018) 'Complex adaptive leadership for organization and human development', in Proceedings of the 55th Annual Eastern Academy of Management Conference, Eastern Academy of Management, Providence, RI, pp.1-14.

Kania, J. and Kramer, M. (2011) 'Collective impact', Stanford Social Innovation Review, Winter, Vol. 9, No. 1, pp.36-41 [online] https://doi.org/10.1007/s13398-014-0173-7.2.

Kania, J. and Kramer, M. (2013) 'Embracing emergence: how collective impact addressing complexity', Stanford Social Innovation Review, Vol. 11, No. 1, pp.1-14.

Kania, J. and Kramer, M. (2015) 'The equity imperative on collective impact', Stanford Social Innovation Review, October, pp.36-41 [online] http://lisd.s3.amazonaws.com/The-EquityImperative-In-Collective-Impact-10052015.pdf on (accessed 6 November 2018).

Kramer, M., Parkhurst, M. and Vaidyanathan, L. (2009) 'Breakthroughs in shared measurement and social impact', FSG Social Impact Advisors and The William and Flora Hewlett Foundation, pp.1-57 [online] http://www.fsg-impact.org/ideas/item/breakthroughs_ in_measurement.html (accessed 7 January 2017).

Ledley, T.S., Gold, A.U., Niepold, F. and McCaffrey, M. (2014) 'Moving toward collective impact in climate change literacy: the climate literacy and energy awareness network (CLEAN)', Journal of Geoscience Education, Vol. 62, No. 3, pp.307-318 [online] https://doi.org/ 10.5408/13-057.1.

Onuoha, F. (2009) 'Why the poor pay with their lives: oil pipeline vandalisation, fires and human security in Nigeria', Disasters, Vol. 33, No. 3, pp.369-389 [online] https://doi.org/ 10.1111/j.0361-3666.2008.01079.x.

Osafo, E. and Yawson, R.M. (2017) 'Leadership development in Ghana: a new look at an old concept', in A. Ardichvili and K. Dirani (Eds.): Leadership Development in Emerging Markets Economies, 1st ed., pp.211-229, Palgrave Macmillan, New York [online] https://doi.org/10.1057/978-1-137-58003-0_12.

Peterson, G. (2009) Wicked Problem Construct: Business and Social Sector Strategies for Global Change, Headwaters Group/Partners for Change, Global, Saint Paul, MN. 
Peterson, G., Yawson, R.M., Sherman, J. and Johnson-Kanda, I. (2018) 'A systems model of using the Deliberate Leadership ${ }^{\circledR}$ framework for addressing wicked problems', International Journal of Business and Systems Research, Vol. 12, No. 3, pp.262-289 [online] https://doi.org/10.1504/IJBSR.2018.091155.

Romme, G. and Dillen, R. (1997) 'Mapping the landscape of organizational learning', European Management Journal, Vol. 15, No. 1, pp.68-78 [online] https://doi.org/10.1016/S0263-2373(96)00075-8.

Stachowiak, S. and Gase, L. (2018) 'Does collective impact really make an impact?', Stanford Social Innovation Review, August, Vol. 8 [online] https://ssir.org/articles/entry/ does_collective_impact_really_make_an_impact (accessed 6 November 2018).

UNDP (1994) Human Development Report 1994, B. Ross-Larson, A. Strong, K. Bieler, J. Peabody, E. Hanlon, D. Sinmao, and M. Bock (Eds.), Oxford University Press, New York, NY.

Vatanpour, H., Khorramnia, A. and Forutan, N. (2013) 'Silo effect a prominence factor to decrease efficiency of pharmaceutical industry', Iranian Journal of Pharmaceutical Research, Vol. 12, SUPPL., pp.203-212.

Wiley, P., Bierly, K., Reeve, T. and Smith, K. (2013) 'When local solutions aren't enough: a strategic funding partnership to restore a large river system', Foundation Review, Vol. 5, No. 1, pp.89-104 [online] https://doi.org/10.4087/FOUNDATIONREVIEW-D-12-00027.1.

Worth, M.J. (2017) Nonprofit Management: Principles and Practice, 4th ed., SAGE Publications, Inc., Thousand Oaks, CA.

Yawson, R.M. and Greiman, B.C. (2014) 'Stakeholder analysis as a tool for systems approach research in HRD', in J. Gedro, D.D. Chapman and K. Guerdat (Eds.): Leading Human Resource Development through Research. Proceedings of the 21st Annual AHRD International Research Conference in the Americas, pp.1-28, Academy of Human Resource Development, Houston, Texas.

Yawson, R.M. and Greiman, B.C. (2016) 'A systems approach to identify skill needs for agrifood nanotechnology: a multiphase mixed methods study', Human Resource Development Quarterly, Vol. 27, No. 4, pp.517-545 [online] https://doi.org/10.1002/hrdq.21266.

Yawson, R.M., Amoa-Awua, W.K., Sutherland, A.J., Smith, D.R. and Noamesi, S.K. (2006) 'Developing a performance measurement framework to enhance the impact orientation of the Food Research Institute, Ghana', $R$ and D Management, Vol. 36, No. 2, pp.161-172 [online] https://doi.org/10.1111/j.1467-9310.2006.00423.x. 